\title{
Scheduling fresh food production networks
}

\author{
Quan Yu, Taravatsadat Nehzati, Carl Philip T. Hedenstierna, Jan Ola Strandhagen \\ Department of Mechanical and Industrial Engineering, Norwegian University of Science and \\ Technology, Trondheim, Norway \\ \{quan.yu, taravatsadat.nehzati, carl.p.hedenstierna, \\ ola.strandhagen\} entnu.no
}

\begin{abstract}
To cope with the high labour costs of developed countries, and volatile market companies aim for flexible machines, that work in parallel in facilities that are dispersed geographically. This paper draws on an example from the food production industry, and investigates how production volumes should be allocated in a heterogeneous network of facilities with parallel machines. Apart from capacity costs, we entertain holding and backlog costs, which are significant due to the undesirability of storing perishable food products at the production facilities. Assuming that a weekly production schedule has been made for the network, we use an interior-point algorithm to optimize the production allocation. Our model takes into account three dimensions: the product, the facility, and the production line. For a network of three facilities, five production lines, and eight products, the optimisation procedure provides a cost reduction potential of $6.9 \%$ compared to the historical costs. Notably, the savings are realized by producing closer to the de-livery date, as the inventory costs of fresh food products outweigh the savings of early production on more efficient equipment. Our contribution is threefold: First, the development of the optimisation procedure, second, the validation of the procedure against historical data, and third, evidence that freshfood production should be responsive to demand and produce close to the delivery date, due to high inventory holding costs in comparison to the cost of capacity.
\end{abstract}

Keywords: Multi-purpose plants $\cdot$ Flexible capacity $\cdot$ Production allocation

\section{Introduction}

A major challenge for producers in high-cost countries is the efficient allocation of labour and the associated payroll costs. In addition to that dealing with volatile market makes companies to stay closer to the market, and therefore distribute production facilities geographically. Typical ways to manage these two problems include the use of parallel machines over network, and there after automation, production levelling, and multi-skilled labour. However, these do not guarantee low total costs unless an appropriate schedule is set for the network [1]. Setting an appropriate schedule for a network is a complicated task that gets more complex when the network is heterogeneous. That is when production facilities are different from each other in terms of machining speed, required operators at each machine, labour cost, etc. This paper investigates how a

adfa, p. 1, 2011.

(C) Springer-Verlag Berlin Heidelberg 2011 
heterogeneous network of flexible production lines can achieve a lower total production cost of production and inventory. In the presented case company, although machines work in parallel across network, the efficiency and labour requirements varies between machines, and the marginal cost of production is subject to step changes when additional machine operators are required. Our investigation reflects the processing and packing operation of a Norwegian producer of fresh-food products, and is limited to one cluster of eight products, produced by five packing lines in three facilities (See Fig. 1).

The aim of this paper is to, first, develop an optimisation procedure, second, to validate the procedure against historical data from a case company, and third, evidently show that fresh-food production should be responsive to demand and produce close to the delivery date, due to high inventory holding costs in comparison to the cost of capacity.

\section{Background}

Operational planning relates to deciding how much to produce of each end product in a facility, commonly with a planning period of 1-2 weeks [2, 3]. In multi-site production planning, decision makers must look at the demand in several locations and make a rough capacity allocation (machines and workforce) before setting a detailed schedule. In other words, the disaggregation of a plan is not done only over time, but also over locations $[4,5]$.

Network planning is often done on an aggregated level, while lower level planning is left to the facilities $[1,6]$. Other approaches for network production planning takes detailed scheduling decisions in the network level $[4,7,8]$. This paper follows the latter approach. We look at short term production scheduling problem for an intra firm production network with parallel machines that facilities have similar distance to customers(i.e. instead of having every facility allocated to specific orders, the customer orders are allocated over the network to minimize the cost of production and inventory)

The multi-location scheduling problem has been optimized as a single-objective problem [9], but single facilties have exploited multiobjective optimisation [10]. Elements like capacity (Labour, and machine), cost of labour (Over time and regular), inventory limits and service level requirement are repeated in majority of models, also represented in this study.

The model proposed in this paper reflects the situation of the case company (a fresh food producer), including a multi-site, multi-product, production environment with multi skilled, flexible workforce that has planning horizon of one week, with two staggered deliveries per week. Combining workforce and production schedule (allocation of orders to machines in each facility) in a multi-site parallel production network makes this study unique compare to other models in the literature. We benefit from studies that address vital elements of this model, such as staggered deliveries [11], flexible workforce [1], and parallel machine [12] in other contexts, and use it in production allocation across production network to reduce costs. 


\section{Problem description}

The case company is a food producer in Norway, having a substantial share of the market, hundreds of end products and a multitude of production facilities. Here we study a limited sample of eight products that are produced in three proximate plants (Fig 1.). Products have different degrees of perishability, from days to months, making stockholding. The products are distributed to serval delivery points.

Production takes place in response to customer orders, with shipments from all three sites due every Wednesday and Sunday morning. Between these days, inventory is accumulated every shift at each site, based on a weekly plan. The facilities are assumed to be geographically close, and any one may be used to satisfy demand. As each production plan covers two sequential shipments, we operate in a setting termed staggered deliveries [2].

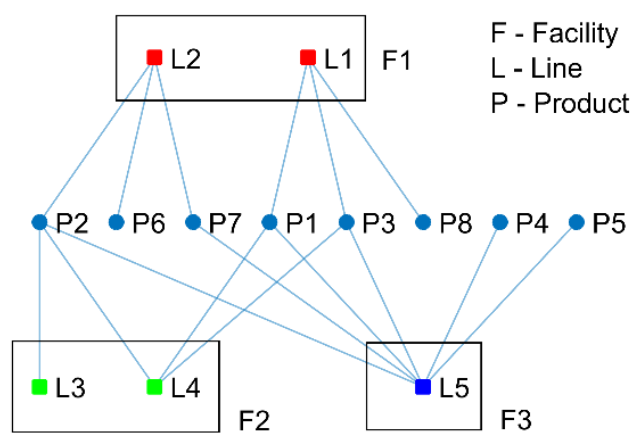

Fig. 1. One cluster of eight products, five lines, and three facilities.

Table 1. Production resources and capacity

\begin{tabular}{|c|c|c|c|c|c|c|c|c|c|c|c|c|c|c|c|c|c|}
\hline \multirow{2}{*}{\multicolumn{2}{|c|}{ Product }} & \multicolumn{8}{|c|}{ Human resource } & \multicolumn{8}{|c|}{ Production Rate (unit/hour) } \\
\hline & & \multirow{2}{*}{\begin{tabular}{|l|}
1 \\
3
\end{tabular}} & \multirow{2}{*}{\begin{tabular}{l|}
2 \\
-
\end{tabular}} & \multirow{2}{*}{\begin{tabular}{l|}
3 \\
3
\end{tabular}} & \multirow{2}{*}{\begin{tabular}{l|}
4 \\
-
\end{tabular}} & \multirow{2}{*}{\begin{tabular}{l|l}
5 & \\
- &.
\end{tabular}} & \multirow{2}{*}{\multicolumn{2}{|c|}{\begin{tabular}{l|l}
6 & 7 \\
- & -
\end{tabular}}} & \multirow{2}{*}{$\frac{8}{3}$} & \multirow{2}{*}{$\frac{1}{2086}$} & \multirow{2}{*}{$\frac{2}{-}$} & \multirow{2}{*}{$\frac{3}{113}$} & \multirow{2}{*}{\begin{tabular}{|l}
4 \\
-
\end{tabular}} & \multirow{2}{*}{$\frac{5}{-}$} & \multirow[t]{2}{*}{6} & \multirow{2}{*}{\begin{tabular}{|l}
7 \\
-
\end{tabular}} & \multirow{2}{*}{\begin{tabular}{|l}
8 \\
1353
\end{tabular}} \\
\hline Facility 1 & Line 1 & & & & & & & & & & & & & & & & \\
\hline & Line 2 & - & 3 & - & - & - & 3 & 3 & - & - & 241 & - & - & - & 1964 & 1780 & - \\
\hline \multirow[t]{2}{*}{ Facility 2} & Line 3 & - & 3 & - & - & - & - & - & - & - & 215 & - & - & - & - & - & - \\
\hline & Line 4 & 3 & 4 & 3 & - & - & - & - & - & 1896 & 202 & 106 & - & - & - & - & - \\
\hline Facility 3 & Line 5 & 4 & 4 & 4 & 3 & 3 & - & 3 & - & 1773 & 210 & 144 & 98 & 1527 & - & 1353 & - \\
\hline
\end{tabular}

By accounting for materials as a holding cost, and considering that line maintenance is done according to a fixed cycle independent of production, the marginal cost of production reduces to the cost of labour. This in turn, is affected by labour laws, as well as the physical characteristics of the operations, and the scheduling. Up to two shifts are worked per day, from Monday to Saturday. Located in Norway, the producer must pay workers for a full shift, regardless of production volume. This includes the weekend shifts on Saturdays, where the compensation is thirty percent higher than on weekdays (Table 2.). While the staff is skilled to operate any line, the lines operate at different 
speeds, have different staffing requirements, and different product-mix capabilities (Table 1). Four dimensions must be taken into account when planning production: facilities, lines, products, and shifts, as shown in Table 3.

Table 2. Production and inventory cost parameters

\begin{tabular}{l|l|l|l|l}
\hline \multirow{2}{*}{ Cost type } & \multicolumn{2}{|l|}{ Inventory } & \multicolumn{2}{l}{ Labour } \\
\cline { 2 - 5 } & Holding cost & backlog & Day 1 to day 5 & Day 6 \\
\hline Value & 1 & 3 & 250 & 300 \\
\hline
\end{tabular}

The required production volumes per product are given once per week, with due dates on Wednesday and Sunday. Production that commences too early receives a holding $\operatorname{cost} h$ per unit a day, while late orders are penalized with a backorder cost $b$ per unit a day.

The product-mix capability, staffing requirement, and capacity vary between the lines, but staff may be allocated to any line, and may transition freely to another line during a shift. Thus, for each facility, the number of workers required for an entire shift is given by the lines running at the busiest part of the shift. Therefore, we calculate the total production time in the shift, for all the active lines of one facility, to find out if the lines must operate in parallel, or if they can work sequentially.

$$
M_{f}=\sum_{l \in f} m_{l} .
$$

As each facility in this case has at most two active lines, we have

$$
W_{f}=\left\{\begin{array}{cc}
\max _{l \in f}\left(w_{l}\right), & M_{f} \leq 6, \\
\sum_{l \in f} \mathrm{w}_{l}, & \text { otherwise. }
\end{array}\right.
$$

Here, the number 6 stands for the hours available per shift. The total labour cost is then accumulated over the whole production network for the shift,

$$
C_{W}=c_{W t} \sum_{f} W_{f}, \quad c_{W t}\left\{\begin{array}{c}
u_{1} \leq t \leq u_{2} \\
u_{3}<t
\end{array}\right.
$$

where $c_{w t}$ is the cost per worker in shift $\mathrm{t}(\mathrm{t}$ suppressed). In this case a different cost is applied to the last shift. The inventory level for a given product and facility is given by the balance equation

$$
i_{t+1}=i_{t}+r_{t}-d_{t}
$$

Holding and backlog costs are applied per unit and shift

$$
C_{\boldsymbol{I}}=c_{\boldsymbol{H}} \cdot \max \left(i_{t}, 0\right)+c_{\boldsymbol{B}} \cdot \max \left(-i_{t}, 0\right) .
$$

We then obtain the total cost for the week by summing inventory costs over shifts, products, and facilities and by summing labour cost by facilities and shifts:

$$
C_{T}=\sum_{f, p, t} C_{I f t}+C_{W p t} .
$$


The cost function contains two main components: The cost of inventory, and the cost of labour. While other costs are associated with production, like maintenance and facility costs, they tend not to be influenced significantly by the schedule, and are therefore excluded from our analysis. When attempting to minimize (6), several constraints must be taken into account:

$$
\begin{array}{ll}
\sum_{l=1}^{L} m_{l f t} \leq h_{f t} & \forall t, f \\
\sum_{t=1}^{T} M_{f t} \leq \sum_{t=1}^{T} \sum_{p=1}^{P} r_{p f t} m_{l f t} & \forall l, f \\
\sum_{l=1}^{L} \sum_{f=1}^{F} r_{p f t} m_{l f t} \leq d_{p t} & \forall p, t \\
\sum_{l=1}^{L} \sum_{f=1}^{F} r_{p f t} m_{l f t} \leq S L_{t} d_{p t} & \forall p, t \\
m_{l f t}, r_{p f t}, M_{f t}, h_{p t} \geq 0 & \forall p, t, f, l
\end{array}
$$

\begin{tabular}{|c|c|c|}
\hline \multicolumn{2}{|c|}{ Name } & Description \\
\hline \multirow{4}{*}{ Indices } & $L$ & Number of production lines $(l=1, \ldots, L)$ \\
\hline & $P$ & Number of products $(p=1, \ldots, P)$ \\
\hline & $F$ & Number of facilities in the network $(f=1, \ldots, F)$ \\
\hline & $T$ & Shift, $(t=1, \ldots, T)$ \\
\hline \multirow{14}{*}{ Parameters } & $d_{p t}$ & Total network demand for product $p$ in shift $t$ \\
\hline & $i_{f t}$ & Inventory level of product $p$ in shift $t$ at facility $f$ \\
\hline & $c_{B t}$ & Backlog cost per shift per unit of product $p$ \\
\hline & $c_{H p}$ & Holding cost per shift per unit of product $p$ \\
\hline & $c_{W t}$ & Labour cost in shift $\mathrm{t}$ \\
\hline & $C_{\text {Ift }}$ & Inventory cost of product $p$, at facility $f$, in shift $t$ \\
\hline & $C_{T}$ & Total inventory and labour cost in a week \\
\hline & $C_{W t}$ & Total labour cost of the network in shift $t$ \\
\hline & $m_{l f t}$ & Operating time (hours) of line $l$ at facility $f$ in shift $t$ \\
\hline & $r_{p f t}$ & Production rate of product $p$ at facility $f$ in shift $t$. \\
\hline & $M_{f t}$ & Total amount of line operating hours in shift $t$ at $f$ \\
\hline & $w_{l t}$ & Amount of labours needed to man line $l$ in shift $t$ \\
\hline & $W_{f}$ & Amount of labours needed at $f$ in shift $t$ \\
\hline & $h_{f t}$ & Number of hours in at facility $f$ in shift $t$ \\
\hline
\end{tabular}

Table 3. Nomenclature

\section{Experimental results}

The delivery frequency is twice per week, i.e., on Wednesday and Saturday. Therefore, weekly demand is calculated from historical production as shown in Table 4. As the historical production plan data is at day level, we used one shift of 12 hours per day in the model to make the historical data and the model output comparable. Table 5 reveals that the model output achieves a significantly lower cost (reduction by $6.9 \%$ ), and that this follows from high production volumes on the day before a shipment is due. Fig. 2 shows how this results in a higher labour cost, but a lower total cost through significant inventory savings. 
Table 4. Demand from historical production (one week)

\begin{tabular}{|c|c|c|c|c|c|c|c|c|c|c|c|c|c|}
\hline \multirow{2}{*}{\multicolumn{2}{|c|}{$\frac{\text { Case }}{\text { Day }}$}} & \multicolumn{6}{|c|}{ Historical production } & \multicolumn{6}{|c|}{ Demand } \\
\hline & & 1 & 2 & 3 & 4 & 5 & 6 & 1 & 2 & 3 & 4 & 5 & 6 \\
\hline \multirow{8}{*}{$\begin{array}{l}\frac{n}{0} \\
\tilde{Z} \\
0 \\
0\end{array}$} & 1 & 18,306 & 12,024 & - & - & - & - & - & - & 30,330 & - & - & - \\
\hline & 2 & - & 61 & 3,097 & 3,935 & 4,247 & - & - & - & 3,158 & - & - & 8,182 \\
\hline & 3 & 1,162 & 1,268 & 228 & - & - & - & - & - & 2,658 & - & - & - \\
\hline & 4 & 480 & - & - & - & - & - & - & - & 480 & - & - & - \\
\hline & 5 & 5,400 & - & - & - & - & - & - & - & 5,400 & - & - & - \\
\hline & 6 & - & - & 10,328 & - & - & - & - & - & 10,328 & - & - & - \\
\hline & 7 & - & - & - & 22,928 & - & - & - & - & - & - & - & 22,928 \\
\hline & 8 & - & 2,196 & - & - & - & - & - & - & 2,196 & - & - & - \\
\hline
\end{tabular}

Table 5. Comparison between historical plan and solution (39 weeks)

\begin{tabular}{c|c|c|r|r|r|r|r|r|r|r|r|r}
\hline Case & \multicolumn{7}{|c|}{ Historical } & \multicolumn{7}{c}{ Solution } \\
\hline Day & \multicolumn{1}{c|}{1} & \multicolumn{1}{c|}{2} & \multicolumn{1}{c|}{3} & \multicolumn{1}{c|}{4} & 5 & 6 & 1 & 2 & 3 & 4 & \multicolumn{1}{c}{5} & \multicolumn{1}{c}{6} \\
\hline Volume & 24,941 & 23,966 & 21,703 & 22,946 & 12,776 & 194 & 5,076 & 14,641 & 51,914 & 3,219 & 7,261 & 30,722 \\
\hline$W_{1}$ & 3.5 & 4.4 & 4.1 & 3.8 & 2.6 & - & 2.5 & 3.7 & 5.6 & 2.2 & 2.5 & 4.3 \\
\hline$W_{2}$ & 3.0 & 3.1 & 3.4 & 3.4 & 2.5 & - & 2.9 & 4.9 & 6.1 & 2.5 & 2.9 & 4.9 \\
\hline$W_{3}$ & 3.3 & 2.7 & 2.4 & 2.4 & 2.2 & 0.1 & 3.2 & 3.9 & 4.0 & 2.8 & 3.1 & 3.8 \\
\hline$C_{H}$ & 24,941 & 48,907 & - & 22,946 & 35,722 & - & 5,076 & 19,718 & 1,315 & 4,292 & 11,538 & 6,386 \\
\hline$C_{\boldsymbol{B}}$ & - & - & - & - & - & - & - & - & 880 & 154 & 110 & 234 \\
\hline$C_{\boldsymbol{W}}$ & 29,692 & 30,615 & 29,769 & 28,769 & 22,000 & 277 & 25,769 & 37,308 & 47,077 & 22,692 & 25,538 & 46,708 \\
\hline$C_{\boldsymbol{T}}$ & 54,634 & 79,522 & 29,769 & 51,715 & 57,722 & 277 & 30,845 & 57,025 & 49,272 & 27,138 & 37,187 & 53,328 \\
\hline
\end{tabular}

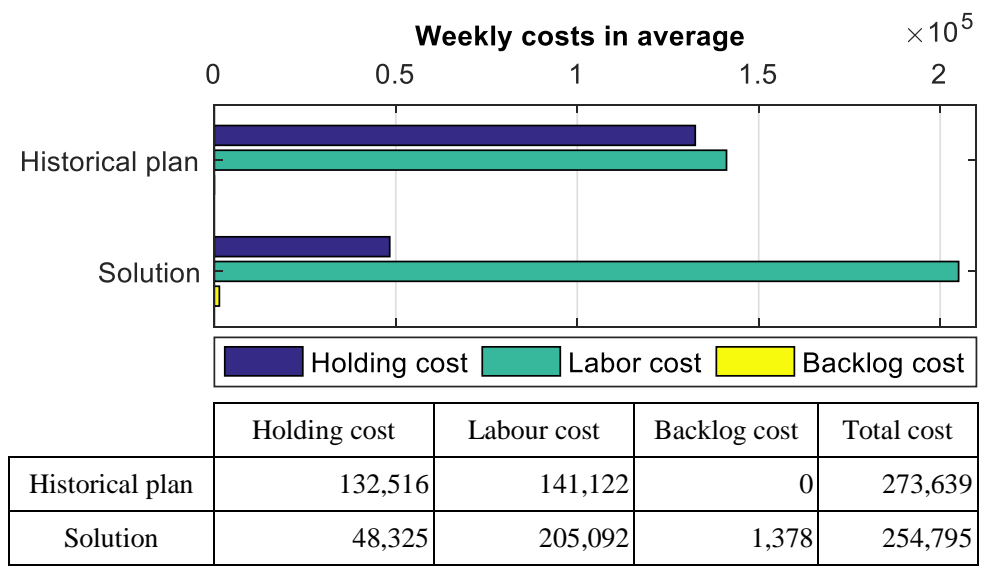

Fig. 2. Average costs of historical plans and solutions (39 weeks) 


\section{Discussion}

Historical production reveals a close balance between holding and labour cost, with no backlogs occurring at all. This reflects a conservative approach to production, which is done well in advance of delivery, using the most efficient equipment to force down labour cost. In contrast, the model solution accepts a much higher labour cost in exchange for an even greater reduction of holding costs. The reason for this is that the daily holding cost ( $2 \%$ of the sales price) is high enough to offset the gains made by producing on the most efficient machinery in advance of the deliveries occurring twice per week. Although labour costs are significant, they are overshadowed by the cost of maintaining perishable inventory. The results given by the scheduling procedure are consistent with the following principles:

1. Determine how much to be delivered on delivery days, and schedule production backwards

2. Produce as late as possible, unless production in previous periods results in savings greater than the additional holding cost.

3. There are integer effects associated with the labour employed in each facility. Use capacity from idle workers - even for operating slow machines.

Occasionally, the historical production figures have exceeded the capacity as indicated by the production rate of the packing lines. This suggests that actual capacity may be higher than indicated, and that further savings may follow if the company maintains accurate data on production rates and capacity.

\section{Conclusion}

We have shown that a procedure for scheduling by reallocating production be-tween facilities can reduce production costs by $6.9 \%$. Although the producer is located in Scandinavia and therefore has high labour costs, the fresh-food products being prduced have such high unit holding costs that production should be made to coincide with shipments, even if this requires the use of slower packing machines. One particular benefit of the algorithm is that it efficiently allocates otherwise idle workers to produce - although they may be operating slow machines, the marginal labour cost of this production is zero.

There are a few limitations to be observed: First, the data quality of machine speeds underestimates capacity, which constrains the algorithm to produce a solution that could lead to higher savings if proper machine speeds were used. Second, the packing plants are assumed to be proximate, and we need not be concerned about delivery lead times, transhipment cost, delivery costs, or raw materials availability. Third, there are no notable setup times or costs. The algorithm could be more generally with the capability to handle setup time. We view these three limitations as opportunities for further research. 
Acknowledgements. This work was supported by the Research Council of Norway through the Qualifish project and SFI Norman program.

\section{References}

1. S. M. J. Mirzapour Al-E-Hashem, A. Baboli, S. J. Sadjadi, and M. B. Aryanezhad, "A multiobjective stochastic production-distribution planning problem in an uncertain environment considering risk and workers productivity," Mathematical Problems in Engineering, vol. 2011, 2011.

2. S. M. Gupta and L. Brennan, "MRP systems under supply and process uncertainty in an integrated shop floor control environment," International Journal of Production Research, vol. 33, pp. 205-220, 1995/01/01 1995.

3. G. H. Saad, "An overview of production planning models: Structural classification and empirical assessment," International Journal of Production Research, vol. 20, pp. 105-114, 1982.

4. A. P. Kanyalkar and G. K. Adil, "Aggregate and detailed production planning integrating procurement and distribution plans in a multi-site environment," International Journal of Production Research, vol. 45, pp. 5329-5353, 2007/11/15 2007.

5. J. T. Lin and Y. Y. Chen, "A multi-site supply network planning problem considering variable time buckets- A TFT-LCD industry case," International Journal of Advanced Manufacturing Technology, vol. 33, pp. 1031-1044, 2007.

6. S. M. J. Mirzapour Al-E-Hashem, A. Baboli, and Z. Sazvar, "A stochastic aggregate production planning model in a green supply chain: Considering flexible lead times, nonlinear purchase and shortage cost functions," European Journal of Operational Research, vol. 230, pp. 26-41, 2013.

7. A. P. Kanyalkar and G. K. Adil *, "An integrated aggregate and detailed planning in a multisite production environment using linear programming," International Journal of Production Research, vol. 43, pp. 4431-4454, 2005/10/15 2005.

8. T. Nehzati, H. C. Dreyer, and J. O. Strandhagen, "Production network flexibility: case study of Norwegian diary production network," Advances in Manufacturing, vol. 3, pp. 151-165, 2015.

9. J. Gjerdrum, N. Shah, and L. G. Papageorgiou, "Fair transfer price and inventory holding policies in two-enterprise supply chains," European Journal of Operational Research, vol. 143, pp. 582-599, 2002.

10. A. S. M. Masud and C. L. Hwang, "An aggregate production planning model and application of three multiple objective decision methods," International Journal of Production Research, vol. 18, pp. 741-752, 1980/11/01 1980.

11. C. P. T. Hedenstierna and S. M. Disney, "Inventory performance under staggered deliveries and autocorrelated demand," European Journal of Operational Research, vol. 249, pp. 1082-1091, 2016.

12. J. Behnamian, "Graph colouring-based algorithm to parallel jobs scheduling on parallel factories," International Journal of Computer Integrated Manufacturing, vol. 29, pp. 622635, 2016/06/02 2016. 